NASA Technical Memorandum 100112

AIAA-87-1946

\title{
The NASA/USAF Arcjet Research and Technology Program
}

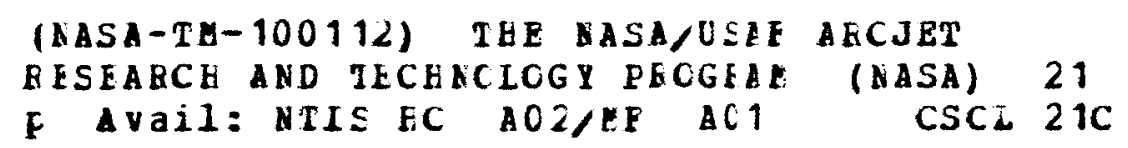

James R. Stone

Lewis Research Center

Cleveland, Ohio

and

Edward S. Huston

USAF Astronautics Laboratory

Edwards, California

Prepared for the

23rd Joint Propulsion Conference cosponsored by the AIAA, SAE, ASME, and ASEE San Diego, California, June 29-July 2, 1987

\section{nusn}




\title{
THE NASA/USAF ARCJET RESEARCH AND TECHNOLOGY PROGRAM
}

\author{
James $R$. Stone \\ National Aeronautics and Space Administration \\ Lewis Research Center \\ Cleveland, Ohio 44135
}

and

Edward S. Huston

USAF Astronautics Laboratory

Edwards, California

\section{SUMMARY}

Direct current arcjets have the potential to provide specific impulses $>500 \mathrm{sec}$ with storable propellants, and $>1000 \mathrm{sec}$ with hydrogen. This level of performance can provide significant benefits for such applications as orbit transfer, station keeping, orbit change, and maneuvering. The simplicity of the arcjet system and its elements of commonality with state-of-the-art resistojet systems offer a relatively low risk transition to these enhanced levels of performance for low power $(0.5$ to $1.5 \mathrm{~kW})$ station keeping applications. Arcjets at power levels of 10 to $30 \mathrm{~kW}$ are potentially applicable to orbit transfer missions. Futhermore, with the anticipated development of space nuclear power systems, arcjets at greater than $100 \mathrm{~kW}$ may become attractive. This paper describes the ongoing NASA/USAF program and describes major recent accomplishments.

\section{INTRODUCTION}

Direct-current arcjets have the potential to provide specific impulses, Isp $>500 \mathrm{sec}$ with storable propellants and $>1000 \mathrm{sec}$ with hydrogen (fig. 1). This level of performance has the potential to provide significant benefits for such applications as orbit transfer, station keeping, orbit change and maneuvering. Because of the broad range of applications and the potential benefits for a number of NASA and USAF missions, the Air Force Astronautics Laboratory (AFAL) and the NASA Lewis Research Center have agreed to pursue a joint research and technology program (refs. 1 and 2 ). It is the goal of the program to advance thruster and systems technologies sufficientiy to demonstrate technology readiness for near-term applications while also developing the fundamental understanding necessary to provide still greater advances in performance. The structure and status of the program are described in this paper, and major results of the $1 \mathrm{~kW}$ class (low power) and $30 \mathrm{~kW}$ class (high power) experiments and studies are summarized.

An arcjet is an electrothermal thruster wherein the propellant is heated by an electric arc as illustrated in figure 2. The high-temperature arc is sustained between the tip of the thermionic cathode and the anode. Ideally, in the conventional design ( $f$ ig. 2 (a)), the arc is forced through the constrictor to a diffuse attachment in the supersonic portion of the nozzle. Thus, the arc is kept away from contact with the other internal surfaces of the 
engine, which alleviates the performance limitations due to material properties of the thruster. An alternative to the conventional, constricted arc design incorporates a mixing chamber between the anode attachment region and the noz$2 l e$, as shown in figure 2 (b). Both the constricted arc and mixing chamber approaches are being investigated.

The power available to auxiliary propulsion on communications satellites is currently limited to about 0.5 to $1.5 \mathrm{~kW}$. Arcjet thrusters operated with storable propellants in that power range should provide significant benefits to the user community. The simplicity of the arcjet system and its elements of commonality with state-of-the-art resistojet systems offer a relatively low risk transition to significantly enhanced performance levels. Successful performance of arcjets in such applications should validate performance and integration approaches and increase the likelihood that the large benefits of arcjets, and other plasma thrusters, may be realized for many other missions. Arcjets at higher power levels on the order of 10 to $30 \mathrm{~kW}$ are potentially attractive for orbit transfer missions. Furthermore, with the anticipated development of space nuclear power systems, arcjets in the $100 \mathrm{~kW}$ range may become viable.

\section{NOMENCLATURE} acceleration due to gravity, $9.81 \mathrm{~m} / \mathrm{sec}^{2}$

Isp specific impulse, $T / \dot{m} g$, sec

Isp,c specific impulse with no power, sec

$\dot{\mathrm{m}}$ mass flow rate, $\mathrm{kg} / \mathrm{sec}$

P input power, $W$

T thrust, $N$

$n$ thrust efficiency $\left(\frac{I_{s p}^{2}}{2 P / g^{2} \dot{m}+I_{s p, c}^{2}}\right)$, dimensioniess

\section{PROGRAM}

It is the goal of this program to advance the technology of arcjet thruster systems and to demonstrate technology readiness for near-term applications while also advancing the technology to enable development of more advanced thruster systems for future missions. The program is organized into four specific tasks, as described below.

\section{Task 1 - System Studies}

These are studies or trade analyses conducted at the systems or subsystems level. Candidate propulsion systems, including arcjets and state-of-the-art 
baseline concepts are compared to define benefits and identify pacing technology needs. The missions selected for analysis include both generic and specific future planned spacecraft. The subsystem studies are conducted to define specific propulsion requirements as well as interface characteristics with other spacecraft subsystems.

\section{Task 2 - State-of-the-Art Characterization}

This effort establishes the current state-of-the-art for both high and low power arcjets. Included are literature survey activities and seminars conducted by established experts in the field. Some experiments on existing thrusters are included to establish lifetime and performance baselines.

\section{Task 3 - Arcjet Research and Technology}

This category of work includes both analytical and experimental activities directed at the process phenomena and component function level. Applied research is underway to develop an understanding of the physical processes that limit component operation. Technology efforts are underway to develop a parametric data base on component performance, to develop engineering design tools, and to optimize component designs.

\section{Task 4 - Systems Technology}

This effort is primarily experimental, involving "breadboard" or "brassboard" propulsion systems and possibly flight tests. Critical components are of an engineering model or flight-type maturity. Testing is conducted to define component interface problems, component interactions, and system level performance for anticipated flight operating conditions, including lifetime, duty cycle, and effluent effects.

\section{Status}

Several system studies have been performed, and the state-of-the-art characterization is essentially complete. The arcjet research and technology is underway in government laboratories, in industry and in academe. The accomplishments of this effort are being incorporated into the initial systems technology efforts. Where appropriate in the following discussion the results are divided into low-power (auxiliary propulsion) and high-power (primary propulsion) classes.

\section{SYSTEM STUDIES}

\section{Primary Propulsion}

Several studies of arcjet orbit transfer missions have been conducted (refs. 3 to 6). Nordley and Vondra indicate that high performance ammonia $\left(I_{s p}>1000 \mathrm{sec}\right.$ ) and hydrogen ( $I_{s p}>1500 \mathrm{sec}$ ) arcjets are attractive for a number of orbit transfer missions (ref. 3). More specifically, significant 
cost savings may be realized for the Global Positioning system through the application of a $900-\mathrm{sec}$ ammonia arcjet to their orbit transfer mission requirements. Even using more a conservative performance estimate ( $I_{S p}=650 \mathrm{sec}$ ) for ammonta, Wang and Staiger show that arcjets could be of interest for Space-Based Radar orbit transfer (ref. 4). Hardy, et al., show that arcjets, as well as ion engines, are viable candidates for the SP-100 Reference Mission, demonstrating electric propulsion in conjunction with a $100-\mathrm{kW}$ class space nuclear power system (ref. 5 ).

\section{Auxiliary Propulsion}

Low-power hydrazine arcjets are very attractive for North-South station keeping on communications satellites because of the reduced propellant requirements (ref. 7). Studies conducted by industry (refs. 8 and 9) are in agreement with these results. Arcjets offer several years of satellite life extension relative to state-of-the-art electrothermal (resistojet) systems (ref. 7 ), as shown in figure 3 . The arcjet performance benefit could alternatively be applied to adding transponders or reducing launch weight, but these alternatives do not appear as attractive as life extension, as shown in figure 4 (ref. 7).

\section{STATE-OF-THE-ART CHARACTERIZATION}

The rekindling of interest in arcjets necessitates a review of earlier work, conducted primarily in th 1960 's. A comprehensive review by wallner and Czika (ref. 10) summarized the state-of-art in 1965. Most of these efforts focussed on the constricted-arc approach (fig. 2 (a)). Power levels investigated ranged from 1 to $200 \mathrm{~kW}$ with propellants including hydrogen, ammonia, lithium hydride, and methane. The most promising performance and life results were in the 10 to $30 \mathrm{~kW}$ range. Although nozzle and electrode erosion were unresolved issues, one $30-\mathrm{kW}$ test ran continuously for $500 \mathrm{hr},($ ref. 11) and another ran intermittently at $30 \mathrm{~kW}$ until being voluntarily terminated with $720 \mathrm{hr}$ of operation (ref. 12). This era of arcjet research and development was terminated because of lack of sufficient electric power in space and the absence of near-term mission requirements. However, during the late 1960's and through the 1970 's, considerable research was conducted on high-pressure arc heaters (ref. 13).

\section{Primary Propulsion}

During the 1950's and early 1960's, arcjet research and development emphasized primary propulsion applications at power levels approximately $30 \mathrm{~kW}$. With hydrogen as the propellant, specific impulse was in the 900 to $1500 \mathrm{sec}$ range, and efficiencies of 0.40 and higher were reported, with 0.55 efficiency using regenerative cooling. Short-term (approximately $50 \mathrm{hr}$ ) storable propellant tests were also performed with ammonia.

Life test of 1960's design. - A significant parameter of state-of-the art arcjets which had to be determined was iffetime. Using one of the best 1960s conventional constricted designs for ammonia arcjets, the Jet Propulsion Laboratory recently performed an arcjet life test under contract to the Air 
Force (refs. 14 to 17). Because of its rellable performance during a $50-\mathrm{hr}$ test in the 1960s, the AVCO Corporation R-3 engine was selected. Improved sealing techniques were used in fabricating the actual engine used in the life test, as the older, previously used techniques were a primary cause of failures on earlier life tests. Where possible, seals were avolded altogether through the means of single piece construction. The cathode and the anode - consisting of the plenum chamber, constrictor and nozzle ... were constructed of 2 percent thoriated tungsten. The plenum backplate was made of high purity boron nitride. The remainder of the thruster body and electrode support features were made of titanium, inconel and molybdenum. During operation, cooling was provided regeneratively by the propellant and radiatively by the anode. The arcjet was operated initially at approximately $28.6 \mathrm{~kW}-265 \mathrm{~A}$ and $108 \mathrm{~V} \mathrm{--}$ and with a propellant mass flow of approximately $0.25 \mathrm{~g} / \mathrm{sec}$. It was found that excessive cathode erosion was occurring at this power level. Therefore, the power was reduced to approximately $25.1 \mathrm{~kW}-210 \mathrm{~A}$ and $120 \mathrm{~V}$.. and the mass flow increased to approximately $0.27 \mathrm{~g} / \mathrm{sec}$. The higher voltage required at the lower power level is due to the decrease in plasma temperature and subsequent decrease in propellant conductivity. The engine was operated at these conditions until it failed after $573 \mathrm{hr}$. At the time of failure, the engine was still operating at an efficiency of 35 percent and a specific impulse of approximately $800 \mathrm{sec}$.

Lessons learned. - While the goal of $1500 \mathrm{hr}$ was not reached, significant lessons were learned from the life test and are described in the following paragraphs.

Facility: Facility problems continue to be a major obstacle to long term testing. Four system shutdowns occurred resulting from various failures or breaks in facility subsystems. During repair of a split in the silicone rubber insulation of the bus bars at $369 \mathrm{hr}$ into the test it was discovered that performance data had been degraded since the 150th $\mathrm{hr}$ because of the effect of silicone oil solidification on thrust measurements. Correction of the solidification problem returned the performance output to levels experienced some $200 \mathrm{hr}$ earlier, indicating that the degradation had been apparent only.

Erosion: Gradual erosion of the cathode tip and anode occurred throughout the test. This erosion was first noted and photographed when the test was interrupted at the $109-\mathrm{hr}$ point due to a faclility failure. The tip of the cathode had eroded into a concave cavity and was surrounded on its periphery by a structure of crystaline growth. The change in the anode was in the form of an increase in constrictor diameter. It is suspected that the erosion was a contributing factor to variations in thruster efficiency which were observed in the latter portion of the test. As crystal growth continued, longer segments of the crystals melted and formed into small balls. These balls were then thrown off of the cathode and impacted on the walls of the nozzle. Serious erosion occurred to the boron nitride propellant injector. This damage was unexpected, based on prevlous tests, and no cause for the erosion has yet been determined.

Termination: Automatic shutdown at the $573 \mathrm{hr}$ point probably resulted from crystal growth which permitted a high current arc to the anode, reducing the operating voltage below the minimum acceptable. Visual inspection of the thruster at that time revealed no serious damage. In the attempt to restart the engine after the inspection, serious damage to the constrictor occurred and 
the test was terminated. This critical damage to the constrictor may have been due to the melting and ejection of crystaline material from the cathode, or the damage could have resulted from the melting of the sharp edges of cracks on the constrictor wall. These cracks, while completely closed during hot operating conditions of the thruster, could have opened during cooling of the thruster after shutdown.

Material: Analysis of the thorlated tungsten cathode after termination of the test indicated that the thorium content near and at all emitting surfaces was very low, possibly zero. Without design changes which could resupply the thorium, users of such an arcjet would have to consider that after some operating time the cathode will be composed of pure tungsten. Erosion of the constrictor occurred in the region of arc attachment. As there was little net mass loss from the anode, it appears that nearly all of the material evaporated from the constrictor was redeposited on the cooler portions of the nozzle wall. Some erosion of the anode may be avoided through additional cooling in future designs. Essentially no damage was experienced by the plenum walls during the life test.

Performance: Comparison of the performance of this copy of the AVCO R-3 engine with that achieved during the 1960s tests confirmed the basic operating regime of this device. Extrapolation of the JPL operating conditions to a $30 \mathrm{~kW}$ power level indicates that the device would produce $2.35 \mathrm{~N}(0.53 \mathrm{lbf})$ at $970 \mathrm{sec}$ specific impulse and at an efficiency of 38 percent. Whether lifelimiting erosion problems at this higher power level can be solved remains to be seen.

\section{Auxiliary Propulsion}

Although the major emphasis of the early arcjet research and development effort was on primary propulsion, some work was performed at power levels typically available for auxiliary propulsion. The Plasmadyne Corporation built a 2-kW, radiation-cooled hydrogen thruster system that was ife-tested for $150 \mathrm{hr}$ at an efficiency of 0.30 and a specific impulse of about $920 \mathrm{sec}$ (ref. 18). This test was voluntarily terminated, and inspection showed little electrode wear. However, the Plasmadyne effort was discontinued without pursuing design optimization, and very little experience was obtained at lower power or with storable propellants such as ammonia or hydrazine.

\section{ARCJET RESEARCH AND TECHNOLOGY}

\section{Primary Propulsion}

The high-power thruster program includes two arcjet performance and life optimization efforts (refs. 19 and 20) and a follow-on effort to design and fabricate a flight type arcjet for a space test. All three efforts build on the high power arcjet technology developed in the 1960s. The 1960s technology was shelved because adequate space power was then unavailable. Since that time, not only has space power technology advanced, but our understanding of high temperature materials, gas dynamics, propellant handling, system controls, and diagnostics has significantly matured. Advances in these technologies have made new attempts at improving arcjet performance and life extremely promising. 
Constricted-arc thruster improvements: Through performance mapping of several arcjet designs, the relationship of operating parameters is now much better understood. Work done to correlate experimental performance data with analytical predictions has enhanced our understanding of the fundamental processes involved and our ability to optimize desired performance characteristics through arcjet design. Comparison of experimental data to the energy balance code Arcjet III revealed that the presence of additional heating of the gas by the arc beyond the constricted region accounted for previously experienced performance prediction errors. On the other hand, discrepancles due to erroneous assumptions in the electrical conductivity of the gas were determined to be minimal. Trends in the efficlency of coupling the electrical power into the gas were also determined. It was found that efficiency dropped as the input power was increased from a starting value of approximately five kilowatts. This was due primarily to the increased ionization and dissociation losses. Thermal and nozzle losses played a lesser role in the decrease in efficiency. Generally, as power was increased the arc current also rose, while the voltage decreased. These relationships are due to the increased ionization that occurs at higher power levels. So, as the level of input power was increased, the incremental gain in thrust diminished, and was reflected in lower specific impulse values. While the correlation of efficiency to input power was not as clear as that of the specific impulse, it tended to generally follow the operating voltage level. These relationships confirmed that a minimally ionized gas will most effectively transfer its energy to thrust. The information gained and confirmed through these experiments strongly suggests that long, high impedence arcs are most effective in heating propellants in arcjets.

\section{Auxiliary Propulsion}

Stability. - The conventional constricted-arc thruster does not always operate in the preferred high-voltage mode lllustrated in figure $5(\mathrm{a})$. In this "high" mode, operation is stable and nondamaging and the $I_{s p}$ is high. In the low mode (fig. 5 (b)), the attachment is at the upstream end of the constrictor in a spot; this mode is characterized by unsteady operation, rapid erosion of the constrictor, and low $I_{s p}$. One way to stabilize operation in the "high" mode is to impart a vortex flow pattern to the propellant entering the arc chamber (fig. 6(a)) (refs. 10,21 and 22). This forces a region of low pressure on the centerline, thereby creating a path of high electrical conductivity for the arc in the desired location. This also provides the benefit of centrifuging the cooler, more dense gas to the walls (ref. 21).

A water-cooled arcjet simulator is used to investigate flow and geometric variations using nitrogen to simulate storable propellants. Both axial and tangential inlets are use to control swirl strength. It is found that tangential injection of the propellant produces stable operation in the high mode. Once this condition is established, axial flow can be added which extends the range of stable operation with little effect on performance. The range of stable, high mode operation is shown in figure $6(\mathrm{~b})$, where input power is plotted against constrictor diameter. Results of demonstrated stable operation obtained with hydrogen arcjets in the 1960's is shown for comparison. Power levels for stable operation are now in the range available for propuision on communications satellites. This tangential injection feature is utilized in hot-wa11 thruster designs. 
Constricted-arc thruster performance. - Performance data are presented over a wide range of power, flow rate, and geometric parameters. Propellants include hydrazine, ammonia, nitrogen, hydrogen, and various gas mixtures. The specific impulse attainable as a function of specific power input is shown in figure 7. Results for propellant grade hyrazine from a flight-type gas generator are shown in figure $7(a)$, (refs. 23 and 24) demonstrating a capability of $I_{s p}>700 \mathrm{sec}$. Changes in geometry have little effect on performance, but may influence the stable operating range. Results for simulated hydrazine gas mixtures (fig. $7($ b), refs. 22,25 and 26 ) show the same trends, but at slightly lower Isp; this is due to the high propellant inlet temperature for hydrazine. (The influence of aging of the catalytic gas generator on the composition of the propellant entering the thruster is also under investigation (refs. 26 and 27)). The simulated ammonia (fig. $7(\mathrm{c})$ ) (refs. 22, 25 and 26) results show similar trends at higher $I_{S p}$ levels, consistent with the decreased molecular mass. The relatively low Isp data seen at $\mathrm{high} P / \dot{\mathrm{m}}$ were obtained at low mass flow and, therefore, low Reynolds number.

of particular interest to spacecraft designers are thrust-to-power ratio, $T / P$, and thrust efficiency, $n$, as a function of $I_{s p}$. The results of figure 7 are replotted in these terms in figures 8 and 9 , respectively. An extensive calorimetric data base from the water-cooled simulator (ref. 21) is also available and is being used to model the energy loss mechanisms.

Arcjets operate at Reynolds numbers considerably lower than even low thrust chemical engines. This is 11 lustrated in figure 10, where Reynolds number is plotted against thrust for a number of specific engines. The combined viscous and compressibility effects lead to large losses, (ref. 28) thick boundary layers, and steep gradients. Experiments are difficult because of the very small dimensions and tolerances, the challenge of measuring low thrusts accurately, and background pressure and pumping speed limitations (ref. 29). Computations are also difficult and time consuming, with the treatment of exit conditions for the mixed subsonic/supersonic flow a major problem.

Constricted-arc thruster life. - Limitation of thruster life, primarily resulting from electrode erosion, is a major technical issue for low-power arcjets. Stable operation achieved with vortex flow, as discussed earlier, and with careful starting techniques is effective in minimizing damage (refs. 30 and 31). The effect of starting on anode damage can be seen in figure 11 , which shows the effect of 30 starts on two different anodes, one run with a weak vortex and unregulated current transients, and the other with a strong vortex and current transient regulation. Much more damage is seen with the weak vortex and poor regulation. Nondamaging start-up is quite clearly dependent on the interaction between the thruster and power processor, as discussed under System Technology. Fundamental cathode emission phenomena are also under investigation, (ref. 32) and the potential usefulness of hollow cathodes assessed. Although hollow cathodes function very well at low pressures, such as in ion engines, stable, long-life operation has not yet been achieved at the pressures required for arcjet operation (refs. 33 and 34 ).

Mixing chamber arcjet results. - The mixing chamber concept (fig. 2(b)) may offer some advantages over the conventional approach, such as higher thrust efficiency and reduced plume/spacecraft interactions. However, the results obtained with the thruster shown in figure 12 are not promising (ref. 35). A comparison of its performance with that of the conventional design is shown in 
figure 13. At the same specific power the $I_{S p}$ is at least $60 \mathrm{sec}$ less than that of the conventional design (fig. 13 (a)). These poor performance results are also shown in terms of $T / P$ versus $I_{s p}(f i g .13(b))$ and $n$ versus $\mathrm{I}_{\text {sp }}$ (fig. 13(c)). Over $100 \mathrm{hr}$ of operation and many starts were performed by this thruster, but the performance was much lower than that of the conventional design.

\section{SYSTEMS TECHNOLOGY}

At this early stage of the program, only the most critical systems issues which are tractable at this stage have been approached.

\section{Primary Propulsion}

Arcjet mission analysis. - A mission study has been performed for the Air Force to identify the optimum propellant, specific impulse, and power level for missions utilizing electric propulsion. This study will directly influence the selection of the propellant and power level to be designed into the Air Force's high power advanced technology arcjet. Both one-way and round-trip, i.e., reusable, propulsion packages were examined, with the electric propulsion device being powered by a nuclear power system.

Power processing. Power must be tailored to arcjet start-up, operation, and control requirements. Toward that end, the Air force has been developing an electronics package for arcjet operation in space. This effort consists of the design, fabrication, demonstration, and delivery of a flight-type, reducedweight power conditioning unit suitable for space operation with a $30 \mathrm{~kW}-\mathrm{class}$ arcjet. The power conditioning unit will be capable of controling the arc current and voltage throughout the entire life cycle of the arcjet. Specifically, the unit must be capable of igniting the arcjet, controlling the initial current following the trigger pulse, and allowing the current to be ramped up to the nominal power level at a prescribed rate. The goals of this effort are to produce a unit operating at an efficiency of 98 percent and a power to mass ratio of $0.2 \mathrm{~kg} / \mathrm{kWe}$. The design currently being pursued uses technology developed and proven for NASA's low power arcjets. This effort has successfully demonstrated smooth start-up of a high power arcjet with a single-phase breadboard (ref. 20).

\section{Auxiliary Propulsion}

Power processing. - The power processer and its integration with the thruster is critical to obtaining reliable, nondamaging starts and stable steady-state operation (refs. 31 and 32,36 to 38). Thus, it is necessary to develop and test basic flight-type power control circuitry along with the experimental thrusters. This approach permits the determination of interface requirements and accelerates the thruster system optimization (ref. 36). The design approach incorporates a closed-loop controlled, high-efficiency, pulsewidth-modulated power converter with an integral automatic starting circuit. An inductor in series with the arcjet serves the dual role of providing instantaneous current control and a high-voltage arc ignition pulse (ref. 36). This design approach gives good performance with several thrusters tested (refs. 36 to 38 ). 
Arcjet/spacecraft interaction. - Areas of concern with respect to the integration of arcjet thrusters onto spacecraft are thermal loading, exhaust plume interactions, and both conducted and radiated electromagnetic interference (EMI). Thermal loading is a function of individual system design and plume characteristics. Improvements in thruster and power processor efficiency will reduce the heat load which must be handled by the spacecraft thermal control system. Plume investigations are underway, and preliminary results are avallable (ref. 39). EMI concerns must be addressed, but experience based on space tests with more highly ionized plumes indicates that any problems should be minor (ref. 40).

\section{CONCLUUDING REMARKS}

The feasibility of low-power arcjets for such applications as satellite stationkeeping is established. Stable and nondamaging starting and steady state operation have been achieved with vortex propellant flow into the thruster and careful integration of the thruster and power processor. Specific impulses up to $730 \mathrm{sec}$ have been demonstrated for a thruster integrated with a flight-type propellant system. Lifetime has been demonstrated in excess of $100 \mathrm{hr}$ with 25 starts at specific impulse over $400 \mathrm{sec}$. In pulsing operation, with $3-\mathrm{sec}$ on and $3-\mathrm{sec}$ off, over 11000 pulses were demonstrated.

At higher power levels, the life of a $25-\mathrm{kW}$ class ammonia arcjet is demon-strated to be over $550 \mathrm{hr}$ at a specific impulse of $800 \mathrm{sec}$, and power processor development is underway.

The investigation of critical integration issues is in progress. Prospects appear good for near-term applications of arcjets to satellite stationkeeping. This should help lower the barriers to application of higher power arcjets and other types of electric propulsion to primary propulsion.

\section{REFERENCES}

1. Vondra, R.J., "U.S. Air Force Development of Electric Propulsion," AIAA Paper 85-1998, Sept.-Oct. 1985.

2. Stone, J.R., "NASA Electrothermal Auxiliary Propulsion Technology," AIAA Paper 86-1703, June 1986. (NASA TM-87281).

3. Nordley, G. and Vondra, R.J., "Electric Propulsion in Near Earth Orbital Maneuvers," AIAA Paper 85-1151, July 1985.

4. Wang, S.Y. and Staiger, P.J., "Primary Propulsion of Electrothermal, Ion, and Chemical Systems for Space-Based Radar Orbit Transfer," AIAA Paper 85-1477, July 1985. (NASA TM-87043).

5. Hardy, T.L., Rawlin, V.K., and Patterson, M.J., "Electric Propulsion Options for the SP-100 Reference Mission," 4th Symposium on Space Nuclear Power Systems, Albuquerque, NM, Jan. 1987. (NASA TM-88918).

6. Deininger, W.D. and Vondra, R.J., "Development of an Arcjet Nuclear Electric Propulsion System for a 1993 Flight Demonstration," AIAA Paper 86-1510, June 1986. 
7. Hardy, T.L., NASA Lewis Research Center, Cleveland, OH, Private Communication, 1986.

8. "Arcjet Experiment Assessment - Technical Report," NASA Contract NAS3-23790, Amendment Mod. No. 16, RCA Aerospace and Defense, Astro-Electronics Division, Princeton, NJ, Jan. 1986.

9. Knowles, S.C., Smith, W.W., Chun, S.I., and Feconda, R.T., "Low Power Hydrazine Arcjets: A System Description for Near-Term Application," 1986 JANNAF Propulsion Meeting, Vol. 1, K.L. Strange and D.S. Eggleston, eds., CPIA-PUBL-455-VOL-1, Chemical Propulsion Information Agency, l.aure1, MD, 1986, pp. 399-408.

10. Wallner, L.E. and Czika, J. Jr., "Arc-Jet Thrustor for Space Propulsion," NASA TN D-2868, 1965.

11. Todd, J.P., "30 kW Arc-Jet Thrustor Research," APL-TDR-64-58, Giannini Scientific Corp, Sant Ana, CA, Mar. 1964. (Avail. NTIS, AD-601534).

12. John, R.R., Connors, J.F., and Bennett, S., "Thirty-Day Endurance Test of a $30 \mathrm{~kW}$ Arc Jet Engine," AIAA Paper 63-274, June 1963.

13. Duncan, D.B., Make1, D.B., and Cann, G.L., "Arcjet Thruster Research and Technology - State-of-the-Art Assessment," Aerojet Techsystems Company, Sacramento, CA, and Technion Inc., Irvine, CA, Feb. 1986.

14. Pivirotto, T.J., King, D.Q., and Brophy, J.R., "Development and Life-Testing of $10 \mathrm{~kW}$ Class Thermal Arcjet Engines," AIAA Paper 85-2031, Sept. 1985.

15. Pivirotto, T.J., King, D.Q., Deininger, W.D., and Brophy, J.R., "The Design and Operating Characteristics of a $30-\mathrm{kW}$ Thermal Arcjet Engine for Space Propulsion," AIAA Paper 86-1508, June 1986.

16. Brophy, J.R. Pivirotto, T.J., and King, O.Q., "Investigation of Arcjet Nozzle Performance," AIAA Paper 85-2016, Sept. 1985.

17. Pivirotto, T.J., King, D.Q., and Deininger, W.D., "Long Duration Test of a $30 \mathrm{~kW}$-Class Thermal Arcjet Engine," AlAA Paper 87-1947, June 1987.

18. McCaughey, 0.J., Geideman, W.A. Jr., and Muller, K., "Research and Advanced Developmerit of a $2 \mathrm{~kW}$ Arc-Jet Thrustor," GRC-1646. Plasmadyne Corp., Santa Ana, CA, 1963. (NASA CR-54035).

19. Cann, G.L. and Pugmire, T.K., "Design of Multikilowatt Arcjets with High Voltage, Fixed Length, Swirl Controlled Arc Discharges," AIAA Paper 86-1509, June 1986.

20. Cassaday, R.J., Britt, E.J., and Meya, R.D., "Performance Testing of a Lightweight $30-\mathrm{kW}$ Arcjet Power Conditioning Unit," AIAA Paper 87-1085, May 1987.

21. Curran, F.M., "An Experimental Study of Energy Loss Mechanisms and Considerations in the Low Power dc Arcjet," AIAA Paper 85-2017, Sept. 1985. (NASA TM-87123). 
22. Curran, F.M. and Nakanishi, S., "Low Power dc Arcjet Operation with Hydrogen/Nitrogen Propellant Mixtures," AIAA Paper 86-1505, June 1986. (NASA TM-87279).

23. Knowles, S.C., et a 1., "Arcjet Research and Technology Phase I," NASA CR- , 1987. to be published.

24. Knowles, S.C., Smith, W.W., Curran, F.M., and Haag, T.W., "Performance Characterization of a Low Power Hydrazine Arcjet," AIAA Paper 87-1057, May 1987.

25. Hardy, T.L. and Curran, F.M., "Low Power dc Arcjet Operation With Hydrogen/Nitrogen/Ammonia Mixtures," AIAA Paper 87-1948, June 1987. (NASA TM-89876).

26. Nakanishi, S., "Experimental Performance of a 1-Kilowatt Arcjet Thruster," AIAA Paper 85-2033, Sept. 1985. (NASA TM-87131).

27. Curran, F.M. and Whalen, M.V., "In-Situ Analysis of Hydrazine Decomposition Products," AIAA Paper 87-2122, June 1987. (NASA TM-89916).

28. Grisnik, S.P., Smith, T.A., and Saltz, L.E., "Experimental Study of Low Reynolds Number Nozzles," AIAA Paper 87-0992, May 1987. (NASA TM-89858).

29. Sovey, J.S., Penko, P.F., Grisnik, S.P., and Whalen, M.V., "Vacuum Chamber Pressure Effects on Thrust Measurements of Low Reynolds Number Nozzles," Journal of Propulsion and Power, Vol. 2, No. 5, Sept.-Oct. 1986, pp. $385-389$.

30. Curran, F.M. and Haag, T.W., "Arcjet Component Conditions Through a Multistart Test," AIAA Paper 87-1060, May 1987. (NASA TM-89857).

31. Simons, M.A., Knowles, S.C., Curran, F.M., and Hardy, T.L., "Low Power Arcjet Life Issues," ALAA Paper 87-1059, May 1987.

32. Mogren, S., "Thermionic and Threshold Emission Studies of LaB $_{6}$," American Physical Society, Mar.-Apr. 1986.

33. Hardy, T.L. and Curran, F.M., "Hollow Cathodes in High Pressure Arc Discharges," AIAA Paper 85.2035, Sept. 1985. (NASA TM-87098).

34. Wilbur, P.J., "Advanced Electric Propulsion and Space Plasma Contactor Research," NASA CR-175119, 1986.

35. Make1, D.B., Jassowski, D.M., Duncan, D.B., Cann, G.L., and McKevitt, F.X., "Arcjet Research and Technology, Phase I, Final Report," NASA CR- , 1987. to be published.

36. Gruber, R.P., "Power Electronics for a 1-kilowatt Arcjet Thruster," AIAA Paper 86-1507, June 1986. (NASA TM-87340).

37. Haag, T.W. and Curran, F.M., "Arcjet Starting Rellability: a Multistart Test on Hydrogen/Nitrogen Mixtures," AIAA Paper 87-1061, May 1987. (NASA TM-89867). 
38. Sarmiento, C.J. and Gruber, R.P. "Low Power Arcjet Thruster Pulse Ignition," AIAA Paper 87-1951, June 1987.

39. Zana, L.M., "Langmuir Probe Surveys of an Arcjet Exhaust," AIAA Paper 87-1950, June 1987. (NASA TM-89924).

40. Sovey, J.S., Zana, L.M., and Knowles, S.C., "Electromagnetic Emission Experiences Using Electric Propulsion Systems - A Summary," AIAA Paper 87-2028, June 1987. (NASA TM-100120).
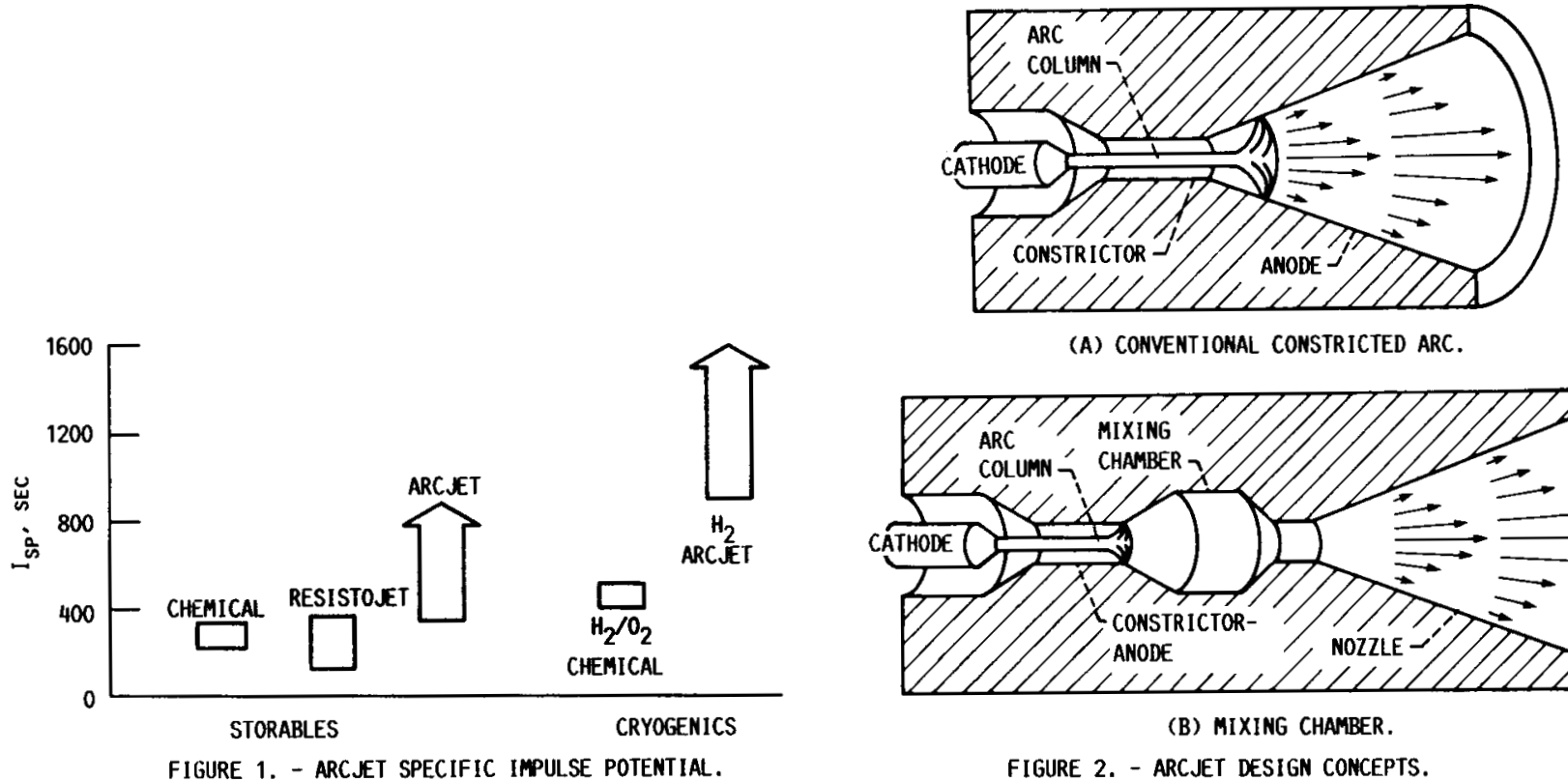

(A) CONVENTIONAL CONSTRICTED ARC.

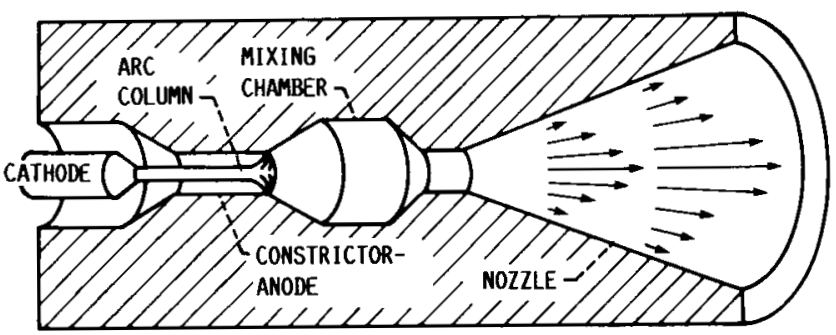

(B) MIXING CHAMBER.

FIGURE 2. - ARCJET DESIGN CONCEPTS.

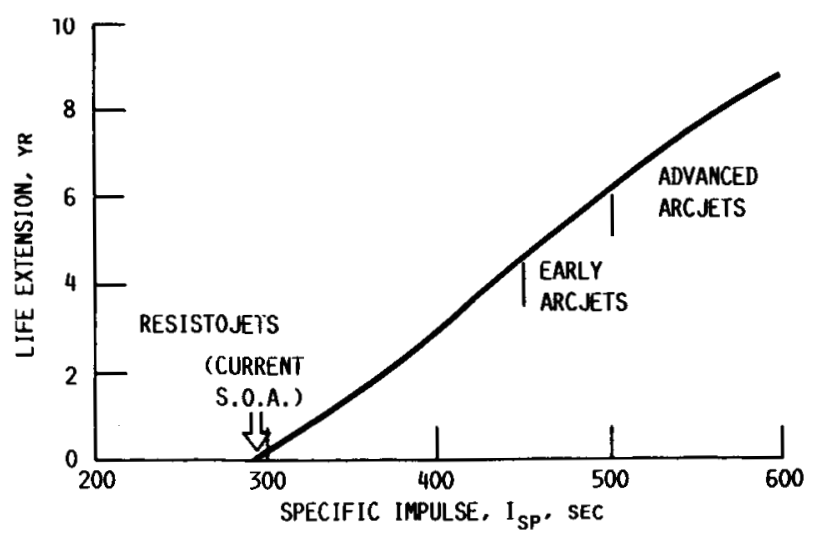

FIGURE 3. - ARCJET AUXILIARY PROPULSION PAYOFF FOR TYPICAL COMMUNICATIONS SATELLITE; INITIAL ON-ORBIT MASS, 1600 KG; HYDRAZINE PROPELLANT (CALCULATIONS INCLUDE TANKAGE AND STRUCTURE). 7

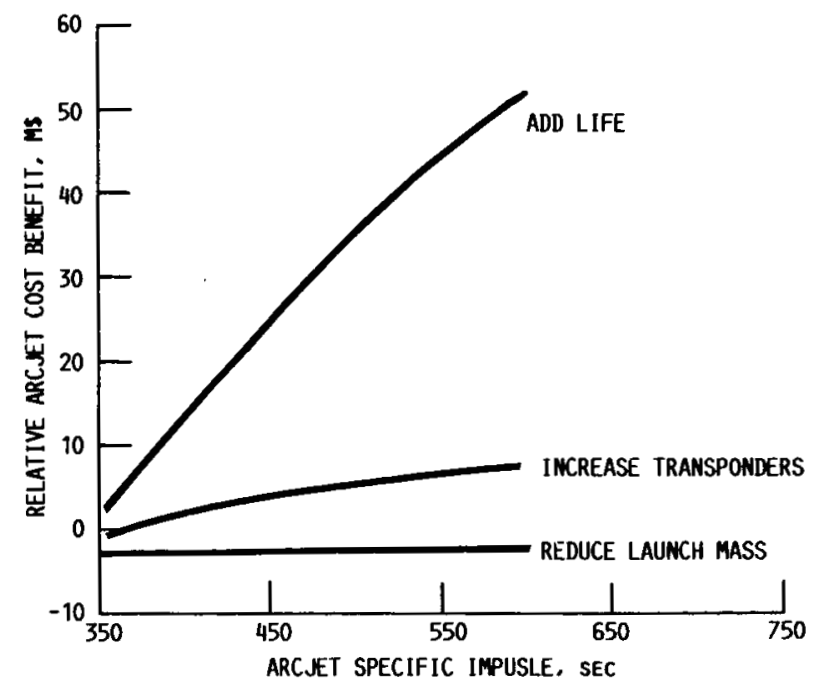

FIGURE 4. - APPLICATION OF MASS BENEFITS FOR A 1-KW HYDRAZINE ARCJET (RELATIVE TO MONOPROPELLANT HYDRAZINE). THRUST EFFICIENCY, 0.35: 1000 KG SPIN STABILIZED (BOL) .7 


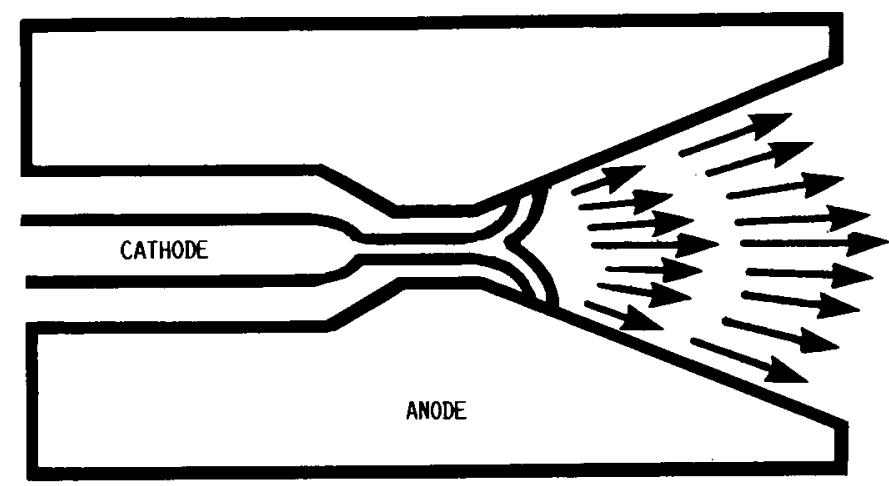

(A) "HIGH MODE".

- diffuse anode attachiment

- stable arc characteristics

- NONDESTRUCTIVE

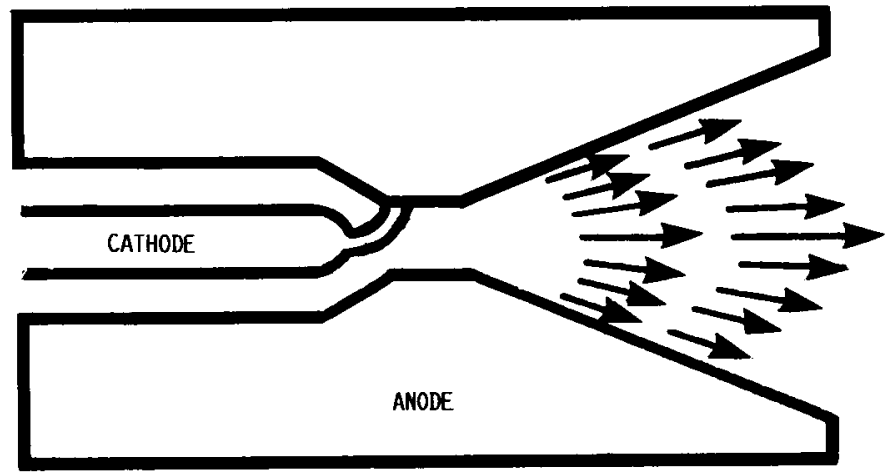

(B) "LOW MODE".

- constricted arc spot

- rapidly varying characteristics

- DESTRUCTIVE

FIGURE 5. - ARCJET MODES OF OPERATION.

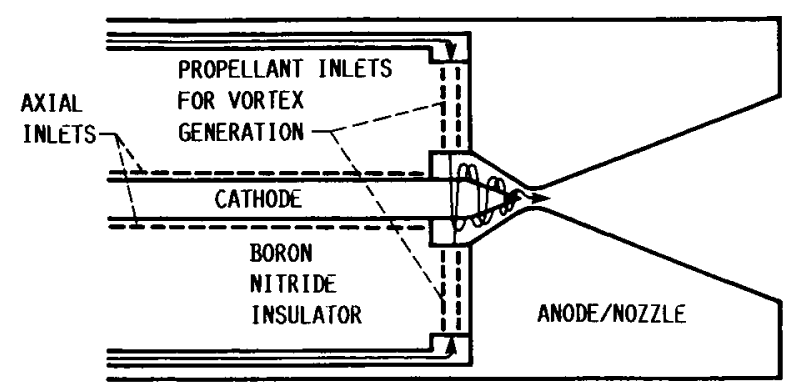

VORTEX PROVIDES:

- Strong radial pressure gradient

- low pRessure chanNel at Constrictor center

FOR ARC TO FOLLOW

- COOL gaS INSULATION OF UPSTREAM ANODE SURFACES

(A) PROPELLANT FEED CONFIGURATION.



(B) EXTENSION OF STABLE OPERATING RANGE.

FIGURE 6. - GAS DYNAMIC STABILIZATION OF ARCJETS. 


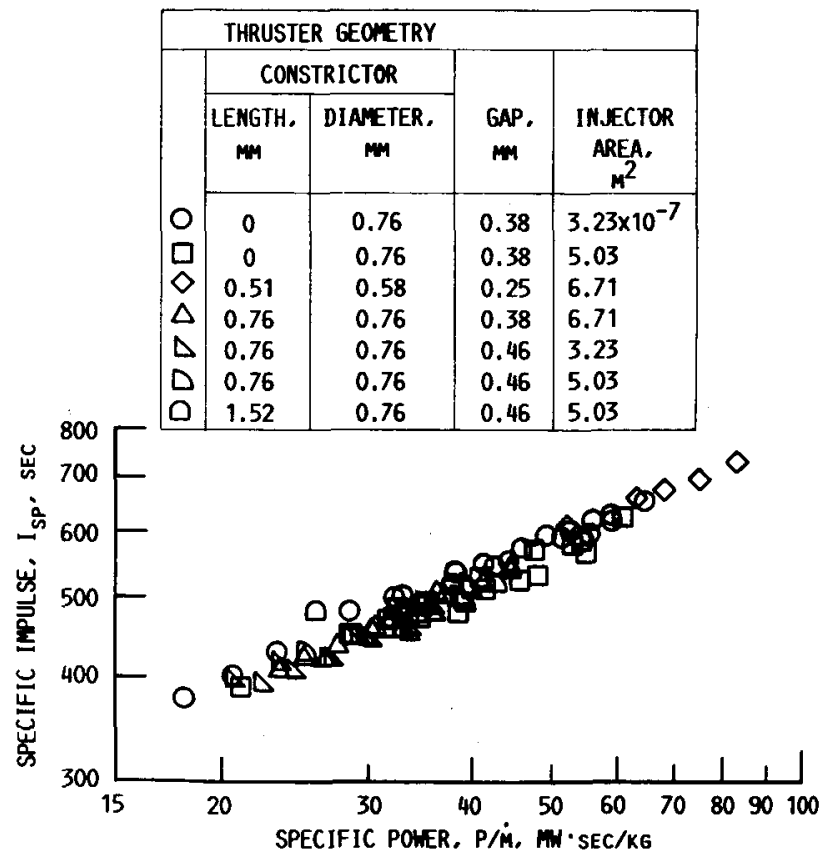

(A) HYDRAZINE FRON FLIGHT-TYPE PROPELLANT SYSTEM (REF. 23), FIGURE 7. - SPECIFIC IMPULSE AS A FUMCTION OF SPECIFIC POWER FOR VARIOUS PROPELLLANTS.

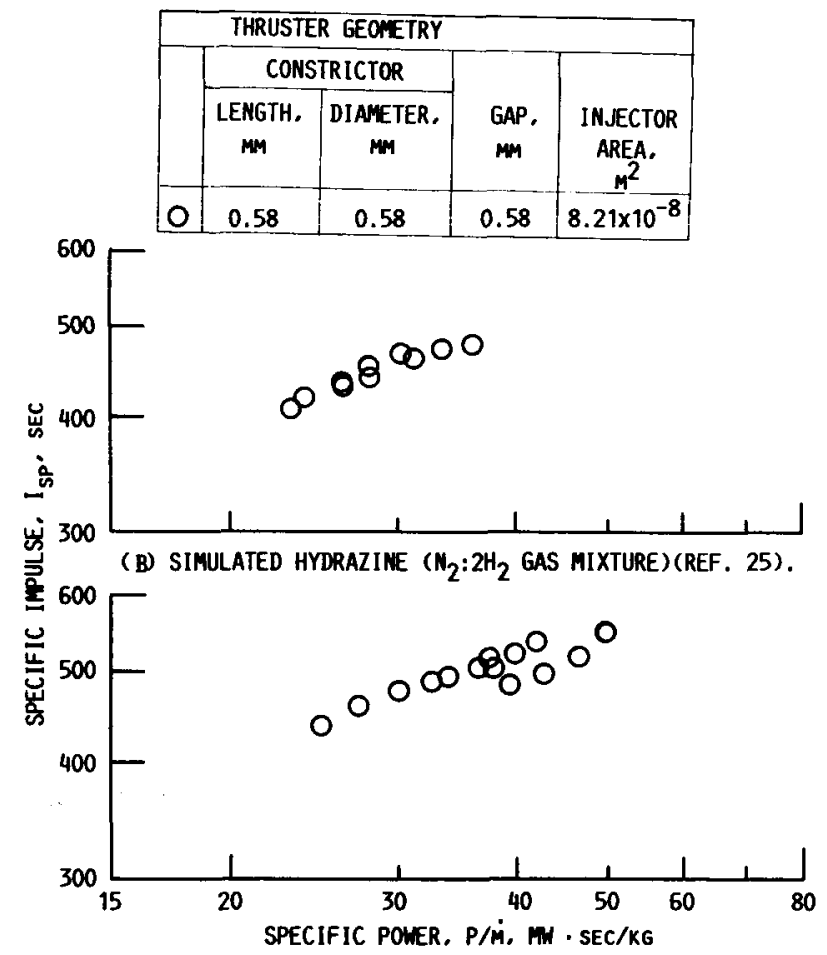

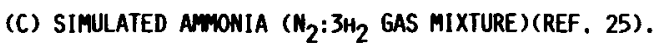
FIGURE 7. - COMCLUDED. 


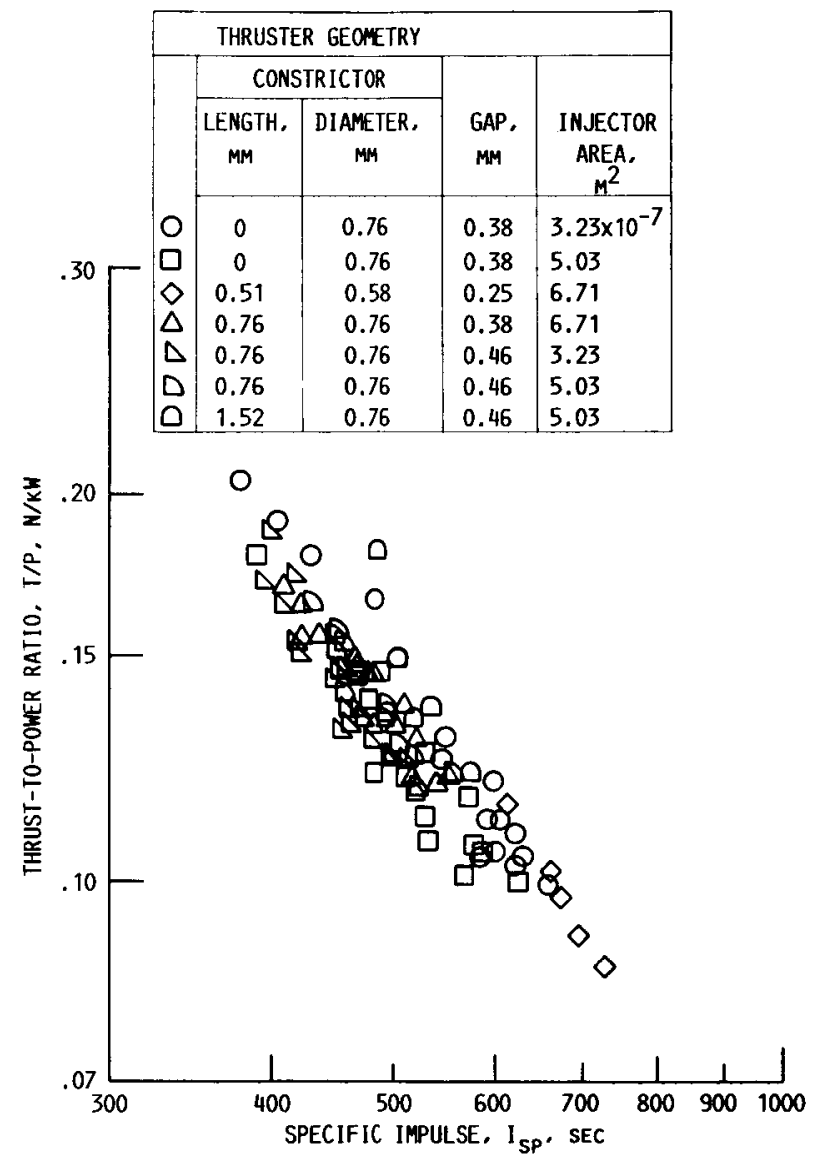

(A) HYDRAZINE FROM FLIGHT-TYPE PROPELLANT SYSTEM (REF, 23). FIGURE 8. - THRUST-TO-POWER RATIO AS A FUNCTION OF SPEIFIC IMPULSE FOR VARIOUS PROPELLANTS.

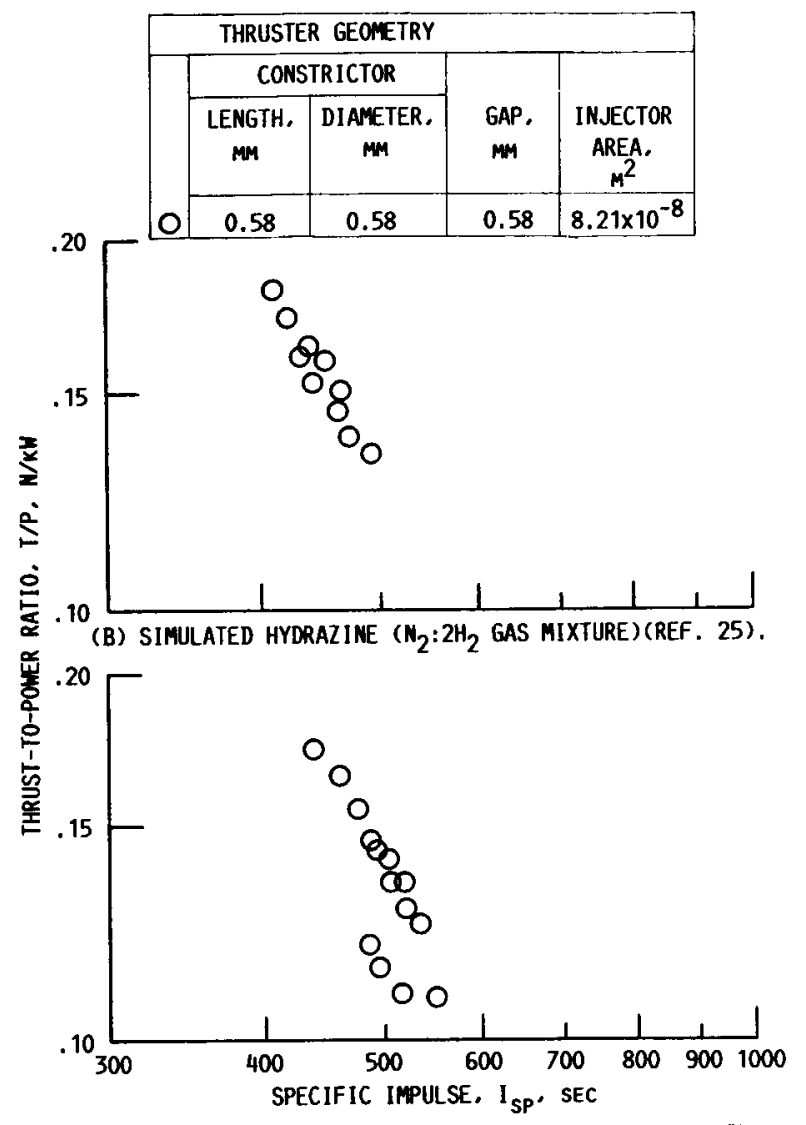

(C) SIMULATEd AMTONIA $\left(\mathrm{N}_{2}: 3 \mathrm{H}_{2}\right.$ GAS MIXTURE)(REF. 25).

FIGURE 8. - COMCLUDED. 


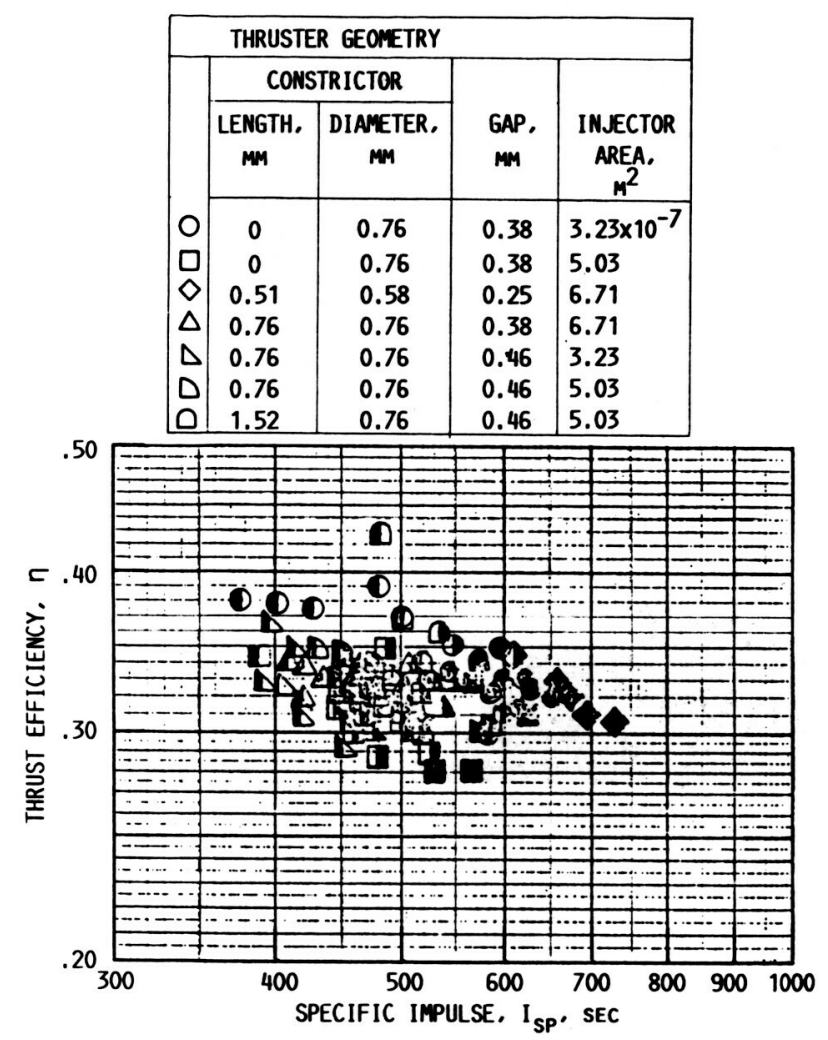

(A) HYDRAZINE FROM FLIGHT-TYPE PROPELLANT SYSTEM (REF. 23).

FIGURE 9. - THRUST EFFICIENCY AS A FUNCTION OF SPECIFIC IMPULSE FOR VARIOUS PROPELLANTS.

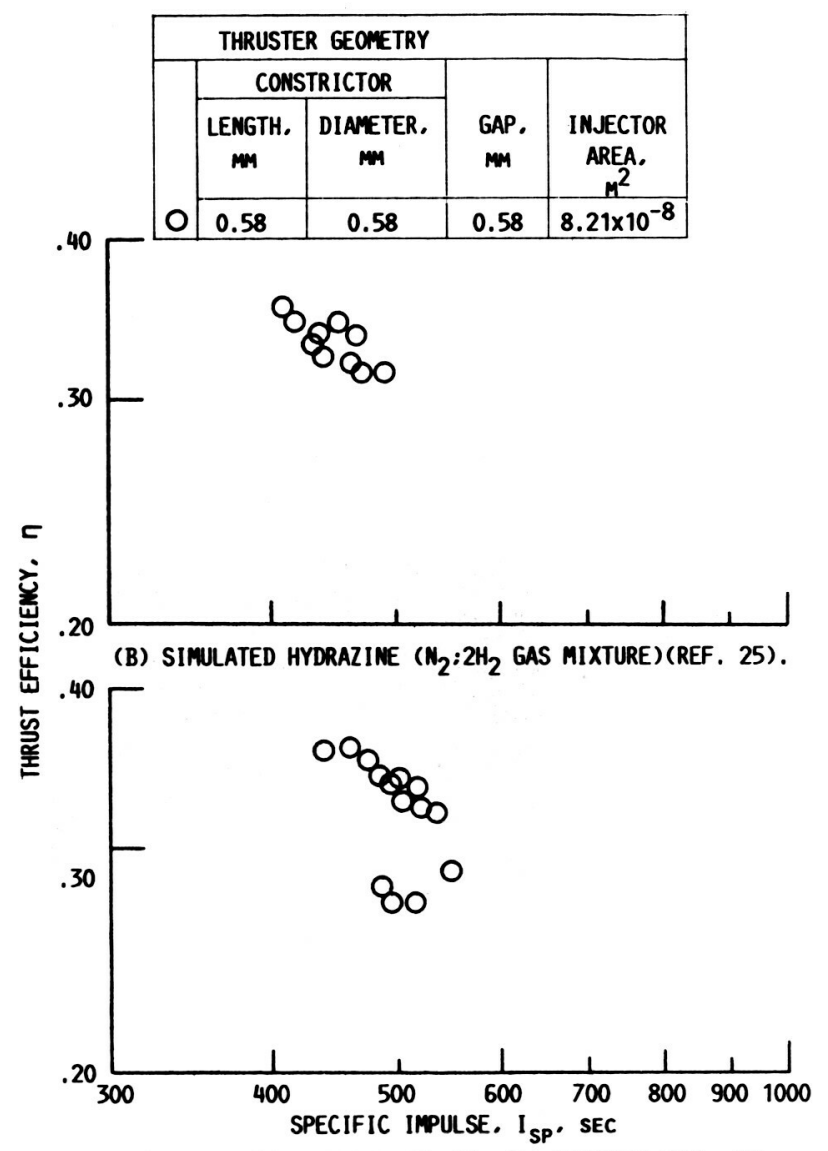

(C) SIMULATEd AMHONIA ( $\mathrm{N}_{2}: 3 \mathrm{H}_{2}$ GAS MIXTURE)(REF. 25). FIGURE 9. - CONCLUDED. 




FIGURE 10. - REYNOLDS NUMBER VERSUS THRUST FOR CHEMICAL AND ELECTROTHERMAL PROPULSION.

〜30 STARTS

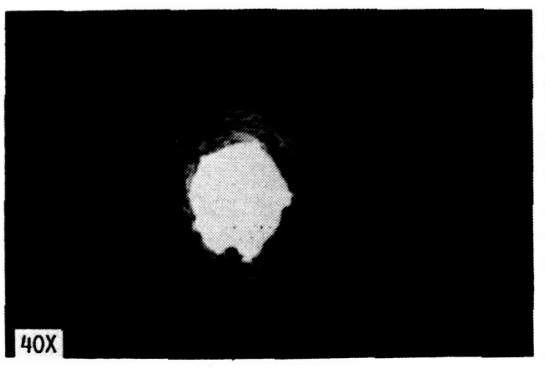

WEAK VORTEX

(A) UNREGULATED CURRENT TRANSIENTS.
- 35 STARTS

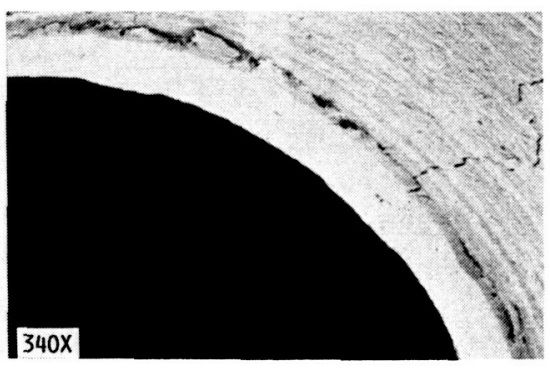

STRONG VORTEX

(B) CURRENT TRANSIENT REGULATION.

FIGURE 11. - ARCJET STARTING AND TRANSITION PHENOMENA: ARCJET FLOWFIELD/POWER CIRCUIT COMBINATION REDUCED STARTUP DAMAGE.

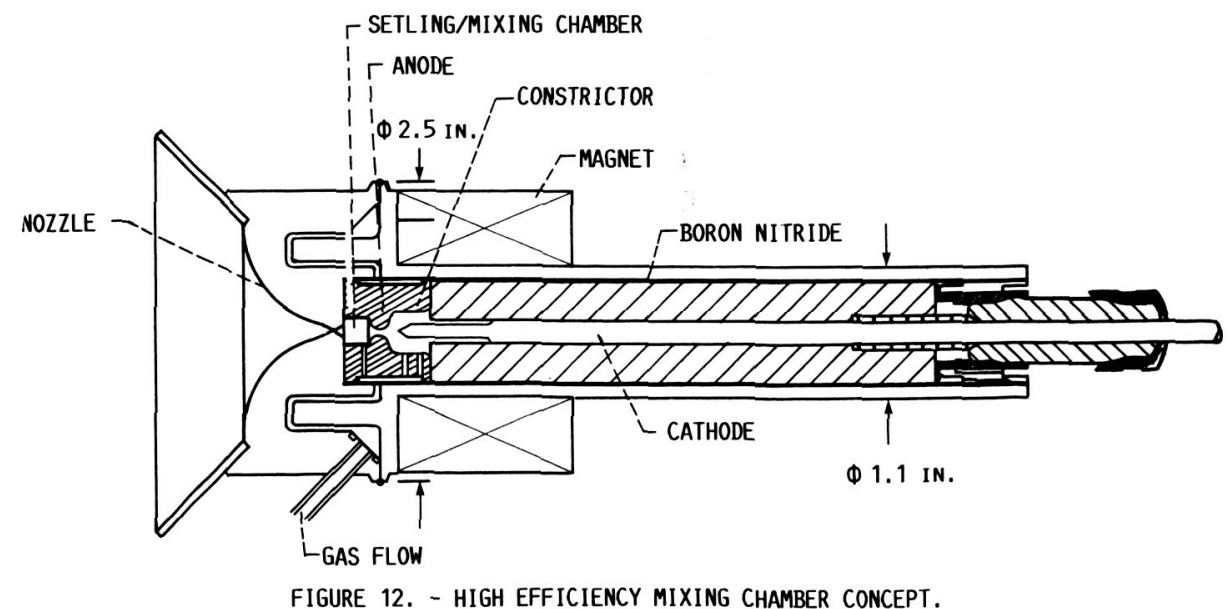




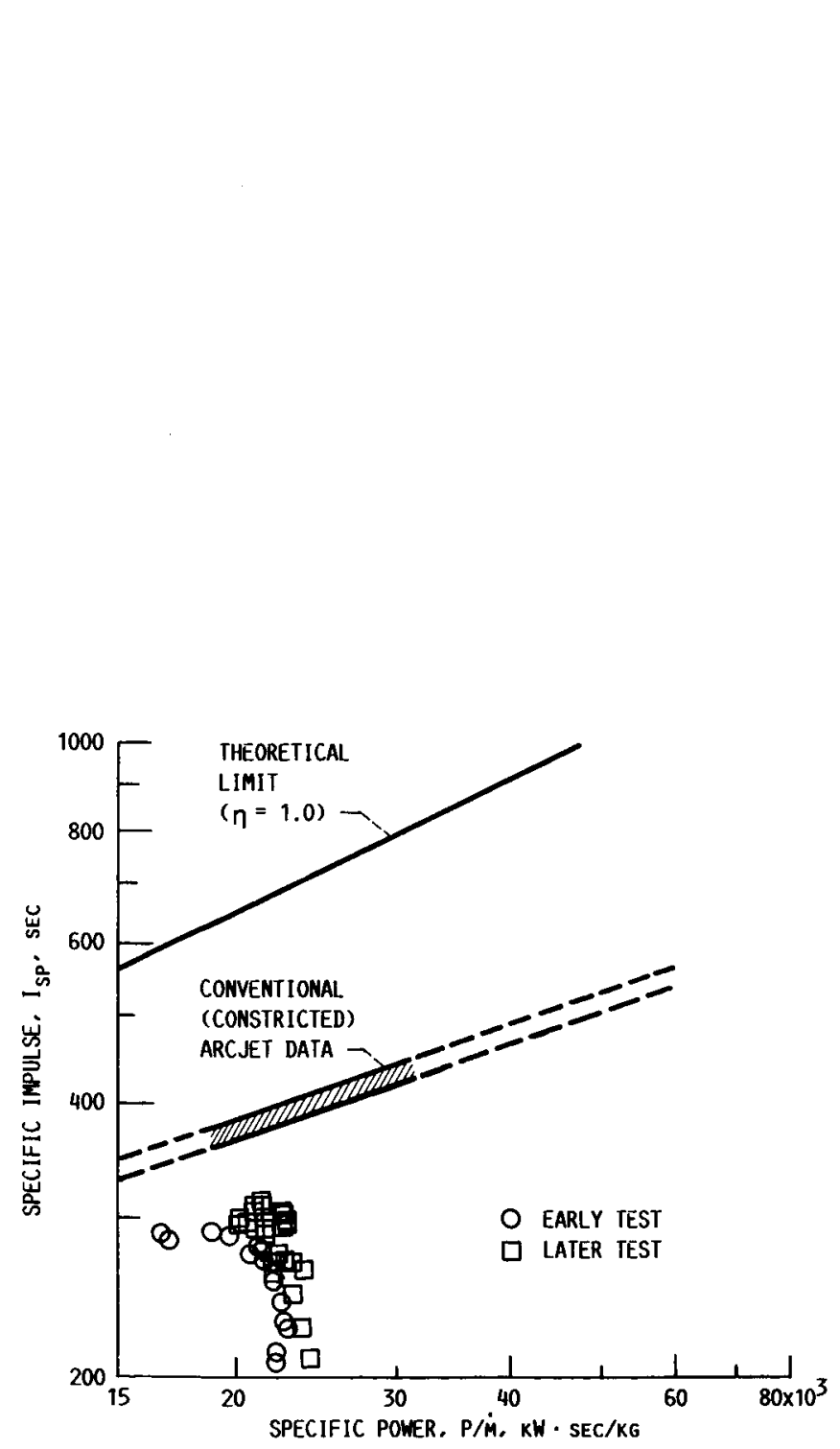

(A) SPECIFIC IMPULSE VERSUS SPECIFIC POWER.

FIGURE 13. - LOW POWER MIXING CHAMBER ARCJET PERFORMAMCE: SIMULATED HYDRAZIME $\left(\mathrm{N}_{2} / 2 \mathrm{H}_{2}\right.$ MIXTURE) AT 0.8 TO $1.4 \mathrm{~kW}$.

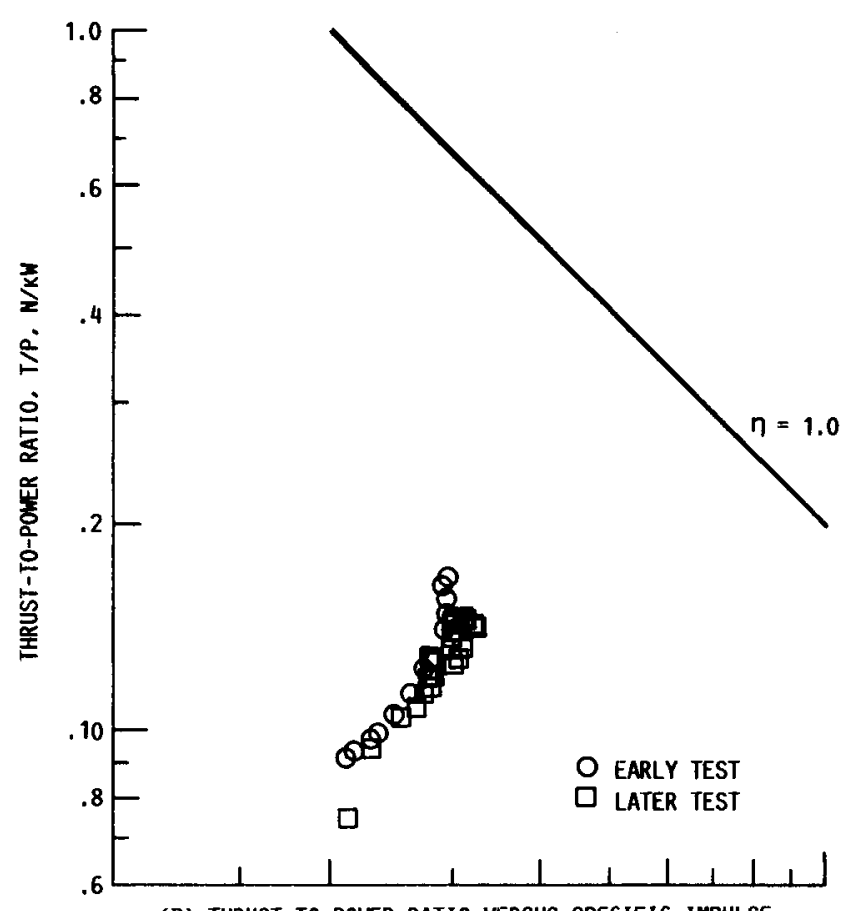

(B) THRUST-TO-POWER RATIO VERSUS SPECIFIC IMPULSE.

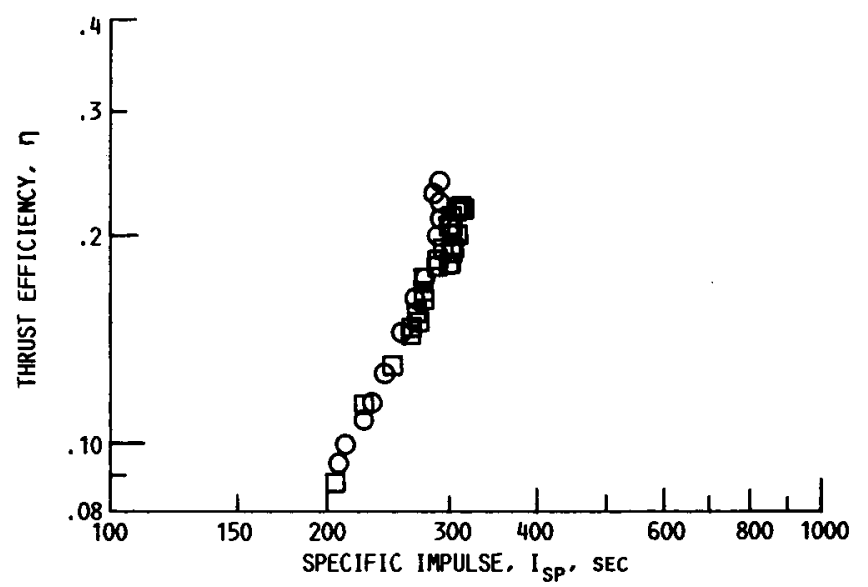

(C) THRUST EFFICIENCY VERSUS SPECIFIC IMPULSE. FIGURE 13. - COMCLUDED. 


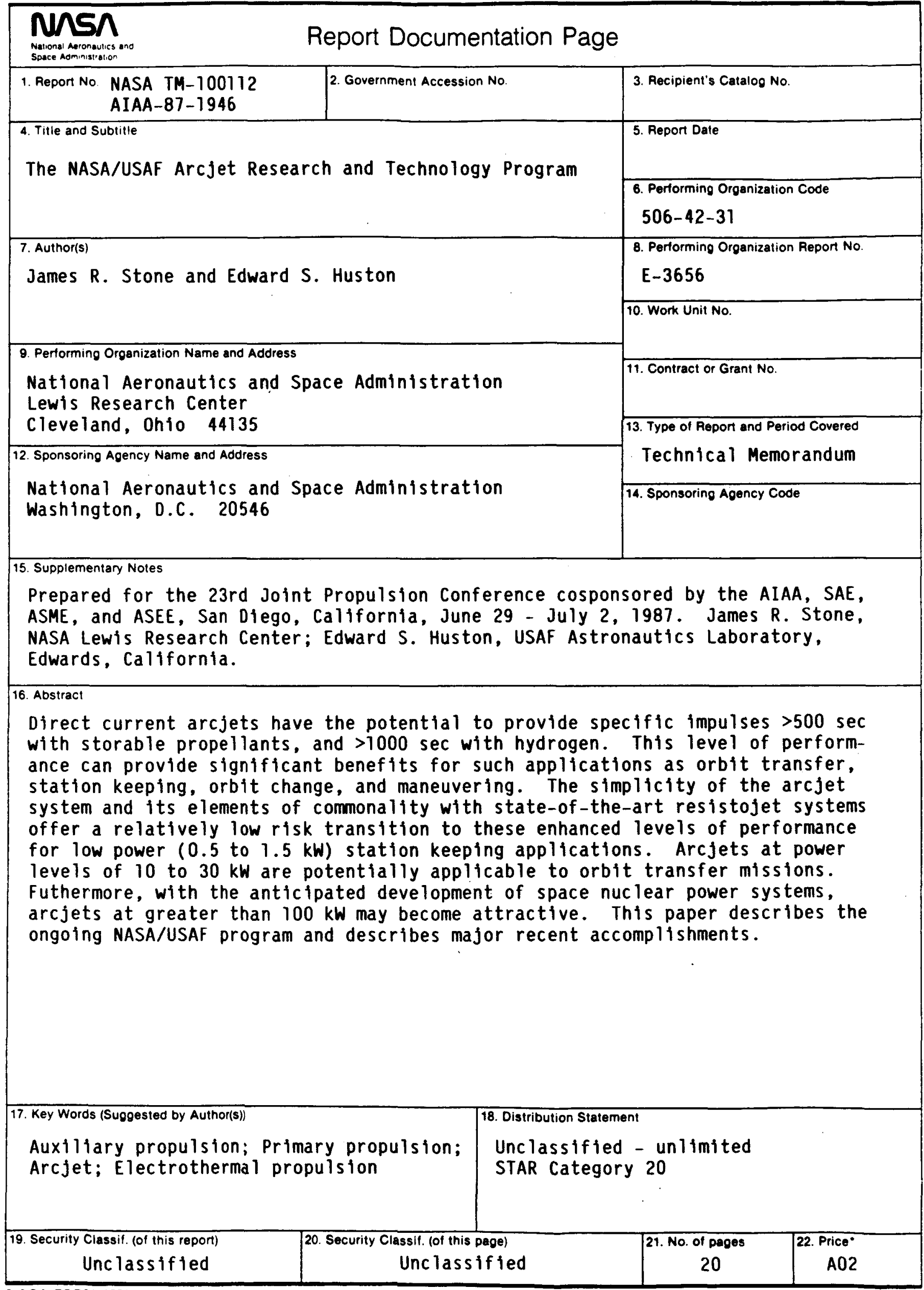

NASA FORM 1626 OCT 86 "For sale by the National Technical Information Service, Springfield, Virginia 22161 